\title{
Health Communication and Obesity Prevention in Hispanic Communities: A Qualitative Exploration of Media's Roles
}

\author{
${ }^{1}$ Roger Figueroa, ${ }^{2}$ Erica Sosa, ${ }^{3}$ Alberto Cordova, ${ }^{4}$ Summer Wilmoth, ${ }^{5}$ Meizi He \\ and ${ }^{6} \mathrm{Sa} \mathrm{Wu}$
}

\author{
${ }^{1}$ University of Illinois, Urbana, USA \\ 2,3,4,5 University of Texas at San Antonio, USA \\ ${ }^{6}$ China Institute of Sport Science, China
}

Correspondence should be addressed to: Meizi He; meizi.he@utsa.edu

Received date: 18 September 2013; Accepted date: 28 November 2013; Published date: 7 February 2014

Academic Editor: Christine Graf

Copyright (C) 2014. Roger Figueroa, Erica Sosa, Alberto Cordova, Summer Wilmoth, Meizi He and Sa Wu. Distributed under Creative Commons CC-BY 3.0

\begin{abstract}
This study qualitatively explored Hispanics' perceptions of obesity and media-related strategies to obesity prevention. Sixteen interviews were conducted with a purposeful sample of Hispanic adults (56\% females; 41 years old) in Texas. The interviews were audiotaped and transcribed verbatim and analysed using inductive content analysis approach. Results showed that participants were aware of the severity and consequences of obesity. Media, especially Spanish TV and Internet were the primary health communication channels. Participants wished for more frequent public health announcements of local government initiatives, programs and events; desired celebrity's role modeling; and suggested media portray of fat body imagery to help the community recognize the seriousness of obesity, as well as demanded for regulations on junk food commercials. In conclusion, future obesity prevention communication should consider using Spanish TV and Internet as the primary channels, utilizing celebrities as message sources, focusing on public health announcements \& messaging; as well as advocating junk food commercial regulation.
\end{abstract}

Keywords: Obesity, Hispanics, Media, Qualitative.

\section{Introduction}

The increasing obesity prevalence in the United States (US) has caused preventable health and economic burdens, particularly affecting Hispanic communities (CDC, 2009). Hispanic adults are considered the minority group with the second-highest obesity prevalence. Obesity in Hispanics has been considered at "staggering proportions", with

Cite this Article as: Roger Figueroa, Erica Sosa, Alberto Cordova, Summer Wilmoth, Meizi He and Sa Wu (2014), " Health Communication and Obesity Prevention in Hispanic Communities: A Qualitative Exploration of Media's Roles," Journal of Research in Obesity, Vol. 2014 (2014), Article ID 722324, 
Hispanic children becoming obese earlier in their lives (National Hispanic Caucus of State Legislators, 2010).

Overweight and obesity increases the likelihood of many chronic diseases such as hypertension, diabetes, heart disease, stroke and some forms of cancer (Azevedo et al., 2006). The top ten causes of death in the Hispanic community include obesity-related diseases (National Hispanic Caucus of State Legislators, 2010). Overall life expectancy for Hispanics is declining due to obesity and obesity-related health risks (National Hispanic Caucus of State Legislators, 2010). Obesity and its health-related issues cause a "disproportionate economic burden" to Hispanics, especially to those with lower socio-economic status; struggling to cover individual and family health care costs (National Hispanic Caucus of State Legislators, 2010). Thus, it highlights the urgent need for effective intervention strategies to reverse this epidemic among Hispanics.

Current research suggests that obesity is the result of complex factors including genetics, lifestyles and others (Crespo et al., 2001). Studies show that certain ethnic groups (e.g., Hispanics) have a genetic predisposition to obesity and diabetes (Hayes et al., 2007). Also, poor eating habits and the lack of physical activity are major contributors to overweight and obesity. Hispanics in the US have a unique demographic profile of low education attainment, low income, and low health insurance coverage, and are predominantly Spanish speakers (U.S. Census Bureau, 2010); which may influence their access to mainstream health information and healthful living opportunities. Moreover, research shows that Hispanics tend to perceive excess weight levels differently than non-Hispanic Whites (Duncan et al., 2011). A recent study in Texas showed that Hispanic women perceived children and women that are "chubby" or overweight as "healthy" (Ramirez et al., 2007). Misperceptions about weight status are associated with less likelihood in or less attempts at weight loss and less physical activity (Duncan et al., 2011). Lack of health information and knowledge (Ramirez et al., 2007), coupled with weight misperception presents a major barrier to lifestyle interventions, accepting emerging public policy changes, and also utilizing environmental initiatives necessary to prevent and manage obesity.

Health communication using media may play an important role informing Hispanics about obesity-related health issues. Research shows that minority groups including Hispanics heavily rely on media compared with other sources for health information (Brodie et al., 1999). Also, most Hispanics speak Spanish at home (U.S. Census Bureau, 2009). Thus, Spanish media may have a greater role than general mainstream media in educating and equipping Hispanics to live a healthier lifestyle.

Effective health communication presents a promising approach in preventing obesity among the Hispanic communities. Based on the Communication-Persuasion Model, the effectiveness of health communication efforts depends on the various inputs and their characteristics (McGuire 1989). Key communication input variables include the channel through which the health message is communicated; sources of the health message, the message itself, and audience factors. Currently, there is a paucity of research on how and to what extent the media are informing obesity-related health issues in Hispanic communities. To this end, the current study was conducted to 1) qualitatively explore the current perception of obesity among the Hispanic communities and 2) seek sights on media-related intervention strategies, in particular channels and sources of message; and the messages for obesity prevention, as well as the Hispanic communities' perception of these messages.

\section{Methodology}

This qualitative study conducted in-depth interviews with a purposeful sample of Hispanics in the Westside of San Antonio, Texas in 2011. The Institute of Research Board at the University of Texas at San Antonio approved the study. The target 
research areas were primarily low-income and educationally disadvantaged Latino neighborhoods with a high prevalence of obesity and diabetes.

\section{Study Participants}

A purposeful sampling (Patton, 1990) strategy was used to recruit Hispanic participants in community settings, including Laundromats and flea markets. Efforts were made to include a heterogeneous sample of participants with diverse characteristics (e.g., gender, age and weight status (normal weight versus overweight or obese). Throughout the data collection process, 27 potential participants were approached to participate by a researcher. Interested participants were screened for study eligibility and were informed of study purposes and procedure. Adults who were over 18 years old and self-report as Hispanics were eligible to participate in this study. Upon verbal consent, the research staff continued with data collection.

\section{Data Collection}

A semi-structured facilitation guide was developed to enquire participants' perception of information channels, sources and media influences pertaining to obesity, as well as their perspective on media's roles on obesity prevention among Hispanics. The facilitation guide was pilot tested with three Hispanic adults and wording was modified to improve clarity.

One bilingual researcher conducted all interviews in Spanish, except one participant who felt more comfortable communicating in English. Interviews took place where the participants were recruited. Interviews lasted from 8 to 20 minutes and were audiotaped. At the end of each interview, the researcher confirmed the participants' responses, using "member-checking" to help improve the accuracy of findings (Patton, 1987).

With the exception of one interview, each interview was transcribed verbatim in Spanish and translated to English, then proofread by another bilingual researcher.
The research team, constantly throughout data collection process, reviewed each transcript until theme saturation was reached (Patton, 1987). At the 16th interview, the research team felt theme saturation occurred and thus, stopped recruiting new participants.

In addition to the interviews, participants filled out a demographic questionnaire. The questionnaire was used to collect information about the participants' age, gender, ethnicity, residency, education, socioeconomic status, language, as well as exposure to general and/or health-related information sources.

\section{Data Analysis}

Data were analyzed using inductive content analysis (Patton, 1987). Inductive content analysis works from specific data to derive broader conclusions without identifying expected outcomes before the data is collected. We used a team approach for data analysis, a technique to ensure study credibility and avoid bias (Patton, 1987). Three researchers, including one bilingual individual, independently reviewed the transcripts, identified themes and developed a preliminary coding template. The research team then met to develop a merged coding template. Two researchers pilot-coded the template on one transcript, using NVivo 9 software. Coding issues that arose during the initial analysis were resolved through consensus within the team.

\section{Results}

\section{Demographic Profiles of Study Participants}

Of the 16 participants, nine lived in the U.S. for over 20 years. The mean age of the sample was 41years with six male and ten female participants. Approximately two thirds were residents of the city of San Antonio for less than 10 years. About half of the participants had some college education. Also, a half of the participants had an individual income below $\$ 22,000$ per year. Spanish was primary language in nearly two thirds of participants. Almost half of the participants reported visiting their doctor or physician seldom and over $1 / 3$ of all 
participants who did so regularly. Spanish language TV was the primary channel for which participants obtained their information. Only one participant reported to have participated in obesity prevention community programs. See Table 1 for additional sample characteristics.

Table 1: Demographic Characteristics of Research Participants, $(n=16)$

\begin{tabular}{|c|c|c|c|}
\hline Characteristics & $\mathbf{n}$ & Characteristics & $\overline{\mathbf{n}}$ \\
\hline Age & & Years in San Antonio & \\
\hline $19-30$ & 6 & $<5$ & 5 \\
\hline $31-40$ & 0 & 6 to 10 & 5 \\
\hline $41-50$ & 5 & 11 to 15 & 1 \\
\hline $51-60$ & 3 & 15 to 20 & 2 \\
\hline $61+$ & 2 & $>20$ & 3 \\
\hline Gender & & Education & \\
\hline Male & 6 & Grade 8 or less & 1 \\
\hline Female & 10 & Some HS & 3 \\
\hline Years in US & & HS Diploma & 4 \\
\hline$<5$ & 1 & Some College & 5 \\
\hline 6 to 10 & 3 & College Degree & 3 \\
\hline 15 to 20 & 3 & Income & \\
\hline$>20$ & 9 & Less than $\$ 22,000$ & 8 \\
\hline & & $\$ 22,001$ to $\$ 45,000$ & 6 \\
\hline & & $\$ 45,001$ to $\$ 75,000$ & 2 \\
\hline Language Generally Spoken & & Language at Home & \\
\hline Both Equally & 3 & Both Equally & 6 \\
\hline More Spanish than English & 6 & More Spanish than English & 2 \\
\hline Spanish & 1 & Spanish & 6 \\
\hline More English than Spanish & 6 & More English than Spanish & 1 \\
\hline English & 0 & English & 1 \\
\hline Language Generally Thinks & & Language with Friends & \\
\hline Both Equally & 3 & Both Equally & 4 \\
\hline More Spanish than English & 3 & More Spanish than English & 3 \\
\hline Spanish & 5 & Spanish & 4 \\
\hline More English than Spanish & 4 & More English than Spanish & 5 \\
\hline English & 1 & English & $\overline{0}$ \\
\hline
\end{tabular}


Figure 1 shows that all participants reported to have access to TV. Internet was the second most accessible media outlet. Two thirds of participants also had access to radio and a half had access to newspapers. Figure 2 shows that $\mathrm{TV}$ and Internet were the preferred media outlets.
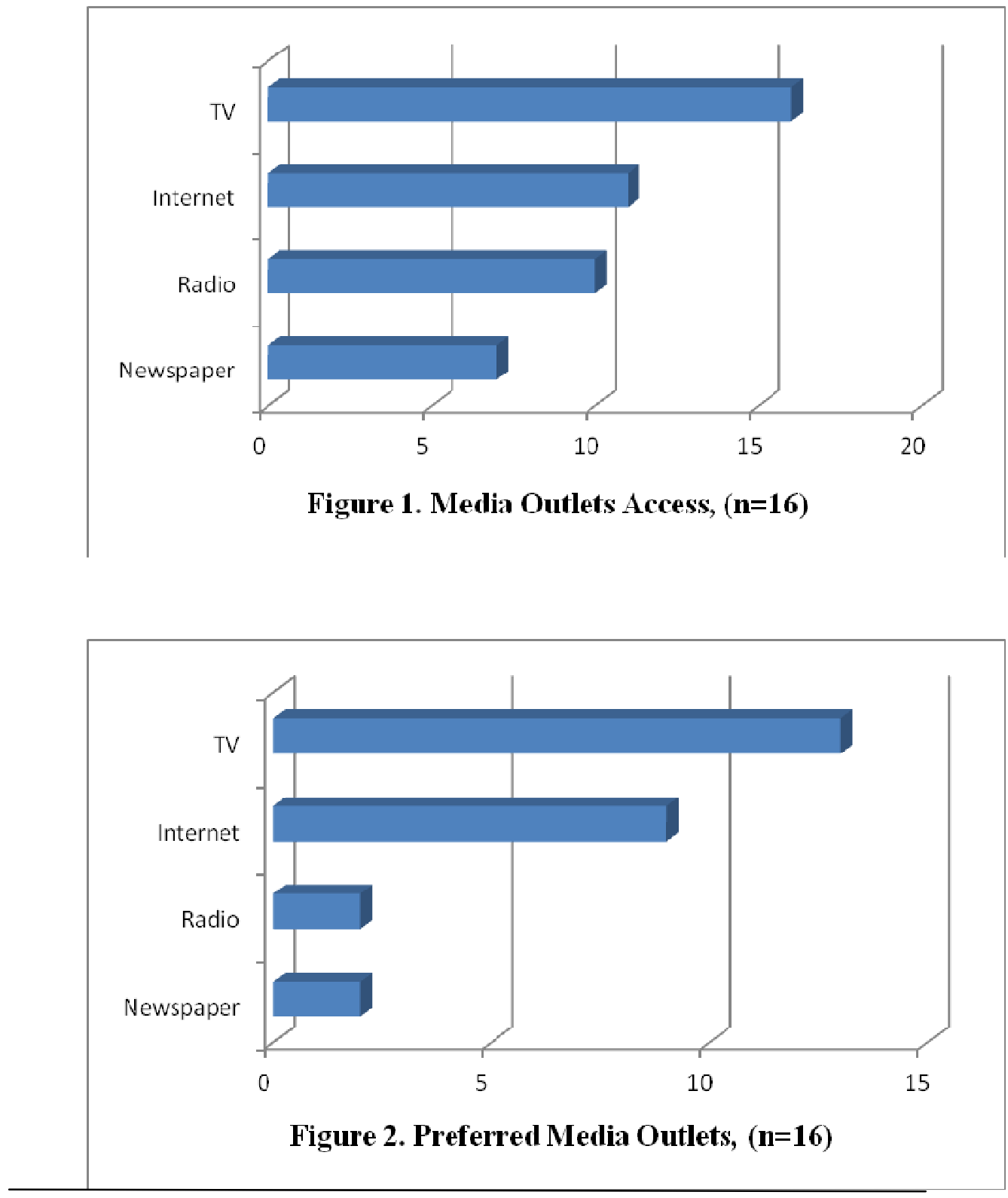

Findings from the Qualitative In-depth Interviews

Findings from the qualitative in depth interviews revealed six key themes. These themes included participants' perceived severity and consequences of obesity among the Hispanic community, perceived causes or contributing factors, message channels pertaining to obesity, health messages and roles of media, as well as other solutions and

Roger Figueroa, Erica Sosa, Alberto Cordova, Summer Wilmoth, Meizi He and Sa Wu (2014), Journal of Research in Obesity, DOI: 10.5171/2014. 722324 
suggestions to obesity prevention and management among the Hispanic population.

Theme 1: Perceived Severity and Consequences of Obesity among the Hispanic Community (Table 2)

Participants were knowledgeable about the severity of the obesity problem in the
Hispanic community. They were aware of the high prevalence of overweight and obesity among Hispanic children and adults. Participants were also aware of the health consequences of obesity such as cardiovascular diseases and diabetes. Some participants expressed concerns for themselves and their families being affected by this health problem.

Table 2: Perceived severity and consequences of obesity among the Hispanic community

\begin{tabular}{|l|l|}
\hline $\begin{array}{l}\text { Prevalence of Overweight and } \\
\text { obesity among children and adults }\end{array}$ & $\begin{array}{l}\text { “..there is more obesity in women and children." } \\
\text { "There are many children with diabetes and is because of } \\
\text { obesity." } \\
\text { "Because here in San Antonio the majority of the time you } \\
\text { see many obese (women) and I guess there are more women } \\
\text { than men in the population or that there is more obesity in } \\
\text { women and children." }\end{array}$ \\
\hline Health Consequences of obesity & $\begin{array}{l}\text { "People with diabetes are very heavy." } \\
\text { "Everything is complicated by obesity." } \\
\text { "Well, that it's wrong, you must get on a diet because if not } \\
\text { things will complicate such as cholesterol and all that." }\end{array}$ \\
\hline "I am afraid for my family, because in my family there are \\
people who are chubby, but very chubby, so I'm afraid that \\
my children follow the same." \\
"I come from chubby families, my mom, my sisters are \\
chubby."
\end{tabular}

Theme 2: Perceived Causes of /Contributing Factors to Obesity (Table 3)

Participants identified a wide-array of contributing factors to the obesity issue in the Hispanic community. Busy life, cultural foods and unhealthy eating habits, lack of determination, and lack of exercise and health knowledge were among the emerging factors identified by the participants. Low socio-economic status and food insecurity were also perceived as risk factors to obesity. Participants articulated that the food industry and the development of technology (e.g. videogames, computers, and multimedia players) also contribute to the obesity problem. 


\begin{tabular}{|c|c|}
\hline \multicolumn{2}{|c|}{ Table 3: Perceived Causes of /Contributing Factors to Obesity } \\
\hline Lack of knowledge & $\begin{array}{l}\text { "I think when you're gaining weight is mostly because you } \\
\text { do not know how to feed yourself." } \\
\text { "I think is because we are not educated well to eat the food } \\
\text { that we are supposed to be eating and to do what we are } \\
\text { supposed to do on a daily basis." } \\
\text { "Because we are not educated. We have not been educated } \\
\text { kids. And I think now we, the parents have to educate our } \\
\text { children from the home, ever since they are little. So they } \\
\text { can learn." }\end{array}$ \\
\hline Junk Food Promotion & $\begin{array}{l}\text { "Also with the kids they give away happy meals, free choice } \\
\text { with this fat food, you know, I think that they should be } \\
\text { able to control and be able to that watch that because it } \\
\text { can get out of hand. Kids, all they see is a toy and they } \\
\text { want that food and that food might not be the best for } \\
\text { them." } \\
\text { "I think it's not good to show many commercials like those } \\
\text { (Junk food commercials)." }\end{array}$ \\
\hline Technology/Videogames & $\begin{array}{l}\text { "To me these games (videogames) ... are not good." } \\
\text { "They play the baseball and football in the television, they } \\
\text { don't go out anymore." } \\
\text { "They come from school and they go to the TV, the } \\
\text { videogames and they are playing there and everything, so } \\
\text { they don't go outside." }\end{array}$ \\
\hline Lack of determination & $\begin{array}{l}\text { "I just know that the programs are out there but we as the } \\
\text { people, we don't really do it, and we are not doing it." } \\
\text { "I have begun to learn that is important to balance } \\
\text { nutrition to deal with overweight but sometimes I do not } \\
\text { apply this to myself." } \\
\text { "...we need to do our part because we are not doing our } \\
\text { part, at least I'm not. And I think that so many Hispanics } \\
\text { don't have discipline." }\end{array}$ \\
\hline Lack of exercise & $\begin{array}{l}\text { "We have poor habits to do exercise." } \\
\text { "I have no time to exercise, for walking." } \\
\text { "...they (children) are not even burning calories; parents } \\
\text { don't even take them to a park or motivate them to do } \\
\text { sports." }\end{array}$ \\
\hline
\end{tabular}




\begin{tabular}{|c|c|}
\hline Busy life & $\begin{array}{l}\text { "It's just that here in San Antonio there are many } \\
\text { restaurants and sometimes people do not have time at } \\
\text { home to cook and all that. Then they look for the fastest, } \\
\text { and the most fast is fast foods." } \\
\text { "...parents themselves have no time because of the busy life } \\
\text { that they live; they must pay bills, and they are working for } \\
\text { a living." } \\
\text { "...some people either too busy working; they don't take } \\
\text { the time to do what we should do for our health." }\end{array}$ \\
\hline Low SES and food insecurity & $\begin{array}{l}\text { "Many families cannot afford to have their children in } \\
\text { dance classes, soccer or whatever." } \\
\text { "... a lot of times we don't eat healthy, sometimes because of } \\
\text { poverty, we eat the cheapest and most economic." } \\
\text { "What doesn't let us do things like that is the price of how } \\
\text { much it costs to become members of the gyms, the } \\
\text { nutritious meals and stuff." } \\
\text { "I find it very, easy to go to restaurants to buy something } \\
\text { for } 99 \text { cents." }\end{array}$ \\
\hline Food Industry & $\begin{array}{l}\text { "The offering of the food here is very abundant for people } \\
\text { and sometimes there are a lot of offers and food is cheap; } \\
\text { that's why people can also buy and slightly exceeds in food } \\
\text { consumption." } \\
\text { "It is easier instead of going home to cook, just going } \\
\text { through a drive-thru and buying something, instead of } \\
\text { cooking something healthy." } \\
\text { "An example is that before the hamburgers had only one } \\
\text { portion of meat, and sometimes double meat. Now there is } \\
\text { triple meat and quadruple. The calories in one of them are } \\
\text { almost } 1000 \text { calories in one of those hamburgers." }\end{array}$ \\
\hline
\end{tabular}

Theme 3: Obesity-related Message Channels and Sources (Table 4)

Participants reported that they obtain healthrelated information and more specific obesity-linked information from a variety of media channels. TV was cited as an important information channel. Internet, newspapers and magazines were also cited as information sources. However, one participant pointed out that there was a fee associated with useful healthy lifestyle information via Internet. Radio appears to be the least used information channel pertaining to obesity. Some participants felt that there was not sufficient media coverage on obesity related topics. Participants also identified other message sources such as doctors, families and friends. 


\begin{tabular}{|c|c|}
\hline \multicolumn{2}{|c|}{ Table 4: Obesity-related message channels and sources } \\
\hline Television (TV) & $\begin{array}{l}\text { "In the Spanish-language channel, they are giving more } \\
\text { information. Like Univision, they showed something about } \\
\text { a walk in a park each week to lose weight." } \\
\text { "Well at least on television; something that caught my } \\
\text { attention is that, at least... the government here in San } \\
\text { Antonio is concerned regarding feeding students." } \\
\text { "The majority information comes from the TV, which } \\
\text { always promotes things like new diet plans, pills, injections, } \\
\text { things like that." }\end{array}$ \\
\hline Internet & $\begin{array}{l}\text { "The Internet has lots of information about this." } \\
\text { "The information that I pull of the Internet, it costs some } \\
\text { money. To try to improve your life, you got to pay." } \\
\text { "I accessed the Internet the other day, where they talk } \\
\text { about the causes of diabetes and obesity was one of the } \\
\text { causes." }\end{array}$ \\
\hline Newspaper/Magazines & $\begin{array}{l}\text { "The newspaper, television has many messages about this." } \\
\text { "Reading it from newspapers and magazines." }\end{array}$ \\
\hline Radio & $\begin{array}{l}\text { "Not much about obesity on the radio." } \\
\text { "The radio doesn't help because you are listening and want } \\
\text { to listen to music" } \\
\text { "The commercials have more effect than advertisement on } \\
\text { the radio and things like that." }\end{array}$ \\
\hline Lack of media coverage on obesity & $\begin{array}{l}\text { "The issue of obesity is hardly seen. I have not seen much." } \\
\text { "...sometimes I do not see that they talk about obesity in } \\
\text { weeks." } \\
\text { "Also, to put information more often." }\end{array}$ \\
\hline Family/Friends & $\begin{array}{l}\text { "I think the families do have a great influence on obesity" } \\
\text { "I know about obesity because of the community, television, } \\
\text { people I talk to and friends." } \\
\text { "What helped me a lot when I came here to the states were } \\
\text { the classes that I took from WIC with my daughters. They } \\
\text { use to, say: "If you give them a glass of" kool-aid, this sugar } \\
\text { is in it." And it was a lot and sometimes you do not know." }\end{array}$ \\
\hline
\end{tabular}

Roger Figueroa, Erica Sosa, Alberto Cordova, Summer Wilmoth, Meizi He and Sa Wu (2014), Journal of Research in Obesity, DOI: 10.5171/2014. 722324 
Doctor/Physician

"...we go to the doctor and he says: 'Do not eat this because this is going to affect you. Eat small portions. Eat everything but measured."'

"When I work with the doctor, I talk to him and ask him what I can do with my family and their lives."

Themes 4: Messages Related to Obesity and Prevention (Table 5)

When asking what obesity-related related messages were out there in the media, participants recalled messages regarding local government's effort on promoting physical activity and school feeding programs. On the other hand, participants pointed out that there were many bad messages, e.g., junk food commercials, diet plans and diet pills advertisement on TV.

\begin{tabular}{|c|c|}
\hline \multicolumn{2}{|c|}{ Table 5: Messages related to obesity and prevention } \\
\hline Positive messages & $\begin{array}{l}\text { "Like Univision, they showed something about a walk in a } \\
\text { park each week to lose weight." } \\
\text { "Segments and that's what I've seen. Tips from a doctor that } \\
\text { appears there and talks about diabetes, cholesterol, blood } \\
\text { pressure; all these things that exist right now." } \\
\text { "What to eat, play, walk more, and work more. This } \\
\text { information is very important. When you look it up, this is } \\
\text { what it says." } \\
\text { "The program "Salud a tu Lado" but they talk very little } \\
\text { about obesity." }\end{array}$ \\
\hline Negative messages & $\begin{array}{l}\text { "The majority information comes from the TV, which always } \\
\text { promotes things like new diet plans, pills, injections, things } \\
\text { like that." } \\
\text { "I think it's not good to show many commercials like those } \\
\text { (junk foods)." } \\
\text { "The commercials have more effect than advertisement on } \\
\text { the radio and things like that." } \\
\text { "...now they show cooking programs on TV, many are } \\
\text { healthy and many others are not." }\end{array}$ \\
\hline
\end{tabular}

Theme 5: Media's Roles on Obesity Prevention in the Hispanic Community (Table 6)

Participants suggested that the community needs health information and education and that the media play an important role in addressing the obesity problem. Participants would like to receive more frequent and intense public health messaging regarding obesity prevention. Role modeling using

Roger Figueroa, Erica Sosa, Alberto Cordova, Summer Wilmoth, Meizi He and Sa Wu (2014), Journal of Research in Obesity, DOI: 10.5171/2014. 722324 
celebrities (e.g. artists and singers) would encourage and motivate the community to take action to live a healthy lifestyle. Acknowledging that the Hispanic community has misperceptions about their weight status, participants offered their insights that it may increase the community's awareness about the severity and consequences of obesity.
They suggested that showing obese people's body image might help people recognize obesity and increase their perceived severity of the obesity problem. Last, but not least, a few participants demanded that junk food commercials needed to be regulated in the media.

\begin{tabular}{|c|c|}
\hline \multicolumn{2}{|c|}{ Table 6: Media's roles on obesity prevention in the Hispanic community } \\
\hline $\begin{array}{l}\text { Frequent Public Health } \\
\text { Announcements }\end{array}$ & $\begin{array}{l}\text { "They should put more things on the radio or on TV to } \\
\text { "market", promote, so people know where to go, how to } \\
\text { participate and so on." } \\
\text { "Only that they must keep announcing it everywhere, on the } \\
\text { media, TV, wherever it can be announced." } \\
\text { "Perhaps more publicity is needed." } \\
\text { "Perhaps it would be good to reinforce more..." }\end{array}$ \\
\hline Role Model Support through Media & $\begin{array}{l}\text { "It seems to me that maybe they would have to motivate } \\
\text { people ... Maybe like: "this artist is going to be there and go } \\
\text { for a walk; or there is going to be this singer and we will } \\
\text { walk together." As they do on TV in channel } 41 \text { then it } \\
\text { would call the attention. We don't need it but that } \\
\text { encourages you, if there is someone there." } \\
\text { "The community as I said, someone to take charge of all } \\
\text { that use the media to come together and talk more about } \\
\text { the subject and that can be effective." }\end{array}$ \\
\hline $\begin{array}{l}\text { Increase awareness on the severity } \\
\text { and consequences of obesity in the } \\
\text { Hispanic community through body } \\
\text { imagery }\end{array}$ & $\begin{array}{l}\text { "A lot of people don't figure out how fat they are or how } \\
\text { they look from behind when they are walking and women } \\
\text { too." } \\
\text { "...more commercials showing the fat people. Showing } \\
\text { them walking with the belly bouncing from up and down. I } \\
\text { think that has a big effect." } \\
\text { "...also show the man with the fat on the side as well, they } \\
\text { will be like: "I look that way". } \\
\text { "I think if they put more commercials of the people that are } \\
\text { obese... If they put more fat people instead of skinny girls in } \\
\text { bikini, put more fat people in bikinis." }\end{array}$ \\
\hline
\end{tabular}

Roger Figueroa, Erica Sosa, Alberto Cordova, Summer Wilmoth, Meizi He and Sa Wu (2014), Journal of Research in Obesity, DOI: 10.5171/2014. 722324 
Regulating junk food commercials

"Right now they (media) limit as far as cigarettes and tobacco and drinking... they (media) should be able to limit that (junk food commercial)."

"I think it's not good to show many commercials like those (junk food)."

Theme 6: Other Suggestions for Obesity Prevention in the Hispanic Community (Table 7)

Participants acknowledged that there were on-going government initiatives and campaigns that help address the obesity problem in the community. They suggested that the government could do more to make schools and the built environment conducive to healthy eating and physical activity. Furthermore, participants articulated a widearray of strategies including school-based initiatives and accessible indoor and outdoor physical activity opportunities. They also emphasized the importance of parental role modeling, peer support and personal responsibility on obesity.

\begin{tabular}{|c|c|}
\hline \multicolumn{2}{|c|}{ Table 7: Other suggestions for obesity prevention in the Hispanic community } \\
\hline Current Government Initiatives & $\begin{array}{l}\text { "I know the city is doing a lot of programs, walking } \\
\text { programs, exercise programs." } \\
\text { "As far as I know, the government is trying to get better food } \\
\text { for the children in school." } \\
\text { "For now, I have seen many campaigns. All that I guess is } \\
\text { the government that does it for the community and all that." }\end{array}$ \\
\hline Future Government Action/Policy & $\begin{array}{l}\text { "So the government and schools should implement so all the } \\
\text { year they have exercise in school." } \\
\text { "If the city was more like 'healthy friendly'. There are parks } \\
\text { and hiking places but for example it is dangerous for cyclists } \\
\text { to ride right now, the traffic is extremely dangerous." } \\
\text { "More Nutritious meal programs for all people who do not } \\
\text { have much money." }\end{array}$ \\
\hline School-based initiatives & $\begin{array}{l}\text { "The teachers have a big influence on the children. They } \\
\text { have to talk to the children about fatness." } \\
\text { "I think schools are starting to feed their kids a little bit } \\
\text { better and I'm hoping that would improve because there } \\
\text { was too much junk food." } \\
\text { "The schools have to teach them and talk with the children, } \\
\text { especially from elementary and junior high school, they } \\
\text { must tell them about looking chubby." }\end{array}$ \\
\hline
\end{tabular}

Roger Figueroa, Erica Sosa, Alberto Cordova, Summer Wilmoth, Meizi He and Sa Wu (2014), Journal of Research in Obesity, DOI: 10.5171/2014. 722324 


\begin{tabular}{|c|c|}
\hline Accessible PA/Gym opportunities & $\begin{array}{l}\text { "Lessons at the gym, classes for people who do not have } \\
\text { much money to participate in things like that. Maybe } \\
\text { something in a park or a gym that you can pay for } \\
\text { something that does not cost much." } \\
\text { "It might be good to make more frequent walks but in other } \\
\text { parks, various parks. Not just in one, and not far away." } \\
\text { "I want something better for people who do not have the } \\
\text { opportunities that other people that can pay for a gym and } \\
\text { that can pay for other things to lose weight." }\end{array}$ \\
\hline $\begin{array}{l}\text { Parents' roles in raising Healthy } \\
\text { children }\end{array}$ & $\begin{array}{l}\text { "I think it would be more towards the parents because } \\
\text { parents are the ones at home and they are who teach their } \\
\text { children regarding food ever since childhood. If the } \\
\text { messages do not reach the parents then the child will eat } \\
\text { what you give him/her." } \\
\text { "I think parents should take an orientation or meetings } \\
\text { where they can get more explanations regarding how to } \\
\text { care for their children to have a healthy life with healthier } \\
\text { meals for their welfare." } \\
\text { "We (housewives) must have the strength to nurture the } \\
\text { family at home and out, the responsibilities, together we } \\
\text { could but we must begin. We have to start, the Latina } \\
\text { moms." }\end{array}$ \\
\hline Peer Support & $\begin{array}{l}\text { "If you could make groups and visit people so they can be a } \\
\text { little healthier." } \\
\text { "Instead of going home to sit and watch TV, go for walks, } \\
\text { meet friends who want to have good health. Participate in } \\
\text { club / gym, just stay busy." } \\
\text { "I think the only thing that would change is having a } \\
\text { personal conversation with someone who is having the } \\
\text { problem because there will always be ads, there will be } \\
\text { things on TV but that does not mean that people will listen } \\
\text { or will take action on the problem of obesity." }\end{array}$ \\
\hline Individual's Responsibility & $\begin{array}{l}\text { "I just think that each one has to do their part and take care } \\
\text { of each one's diet." } \\
\text { "We should eat food to nourish our body." } \\
\text { "So I think to do more things in the future, do more things } \\
\text { to start to eat more nutritious, do more things in the gym, } \\
\text { run more, and so on." }\end{array}$ \\
\hline
\end{tabular}

Roger Figueroa, Erica Sosa, Alberto Cordova, Summer Wilmoth, Meizi He and Sa Wu (2014), Journal of Research in Obesity, DOI: 10.5171/2014. 722324 


\section{Discussion}

The aim of the study was to 1) qualitatively explore the current perception of obesity among the Hispanic communities in San Antonio, and 2) identify media-related intervention strategies including channel, sources of message and communities' perception of existing media messages related to obesity. Results from this study showed that participants were aware of the severity and consequences of obesity as well as the contributing factors in their community. Media, especially Spanish TV, and Internet were the primary channels. Participants perceived both positive and negative messages that impacted the Hispanic communities on obesity-related health issues. Participants expressed that media could play an important role in informing, educating and motivating the Hispanic community to adopt a healthier lifestyle and reduce obesity risk.

Overall, participants in this study understood the severity, consequences and contributing factors of obesity among Hispanics. A recent qualitative study in Texas with community center workers serving children and families in a predominantly Hispanic, low-income neighborhood also reported that participants recognized obesity as a problem and identified healthy eating and physical activity to manage the problem (Chatterjee et al., 2005). Consistent with the literature (Contento, Basch \& Zybert, 2003; NHCSL, 2010; Duncan et al., 2011), participants in the current study did point out that many community members were not aware of their own weight problem and called for education through the media to help address this health problem.

Consistent with other research, the current study suggested that media, especially Spanish-language TV and Internet were important health communication channels for this target population (Center for Spanish Language Media, 2011). The majority of participants in the current study had access to and preferred TV and Internet for obesityrelated health messages over newspaper and radio. Brodie and colleagues (1999) also identified TV as the most common and most preferred health information outlet among all media. Another recent survey found that Hispanics who are not comfortable speaking English have lower trust and lower general mainstream media use patterns than their counterparts who are more comfortable speaking English (Clayman et al., 2010). This may imply that Spanish media are more attractive to predominantly Spanish speakers. Furthermore, the authors suggested that the poorer, less educated Hispanics might be especially receptive to messages given through aural and visual channels, including TV (Clayman et al., 2010). In a study by Vargas \& De Pyssler (1999), researchers analyzed the content of major Spanish newspapers and concluded that these ethnic newspapers fell short on operating as health communication channels. Nonetheless, Spanish-language TV and Internet could serve as better channels to deliver obesity prevention messages than newspaper or radio.

Participants in the current study recognized the impact of media messages, negatively or positively, pertaining to obesity among Hispanics. On one side, participants in this study reported concern with the promotion of diet pills, diet plans and junk food on television. Recent data suggests advertisers spend more than $\$ 566$ million on food, beverage and restaurant advertising through Spanish media (Brown et al., 2008). Lobbying and advocacy for junk food commercial regulations represent an important media-related strategy to prevent against obesity among the Hispanic communities.

On the positive side, participants felt that media could play an important role in informing and motivating the Hispanic community to live a healthier lifestyle and reduce the risk of obesity and diabetes. A lack of health knowledge and determination to change health behaviors were identified as important contributing factors to obesity, which are aligned with findings from another study in the Hispanic community (Ramirez et 
al., 2007). In addition, the unique demographic profiles of low education, low income and low health insurance coverage rate among Hispanics further the importance of media in informing, educating and motivating the community to address the obesity-related health issues. Brodie et al (1999) reported that Hispanics relied heavily on media for health information a decade ago. Although participants in the current study felt that there was insufficient media coverage in regards to obesity, they did recall positive health messages from Spanish language TV such as public health announcements promoting local physical activity events, and healthy eating messages. Participants asked for more and frequent public health announcement, positive health messaging, including TV shows that offer practical tips and healthy cooking demonstrations. The community also appreciated reliable but free health information from diverse media sources including the Internet. To tackle the lack of self-determination in this community, participants suggested that using celebrity role models as the message sources could motivate the community to take health action. For instance, having a famous artist or singer showing up to local physical activity events would motivate the less-determined community members' to participate in such activities. These suggestions of role modeling of celebrities coincide with a recent Texas Spanish-language TV media campaign which showcased the role of models and experts that are relevant and credible to the audience to providing useful obesity prevention information and messages (Reminger et al., 2010).

Among the suggested media-related strategies, participants articulated the usage of "fat body image" to help the community recognize the seriousness of the obesity problem. This was an interesting but very sensitive topic. Based on the Health Belief Model, visual imaging of a severe disease and its consequences can be an effective strategy to heighten people's perceived severity and vulnerability of that particular disease, thus increasing the likelihood of individuals taking preventive actions (Windschitl, 2003). A recent Dutch media campaign that used TV commercials to portray the "danger of gaining $1 \mathrm{~kg}$ a year" was effective in increasing obesity awareness, creating more positive attitudes and motivating individuals with lower risk perceptions and increasing efficacy for preventing weight gain (Wammes et al., 2007). However, because research has consistently suggested that obese people often experience psychological stress and social stigma (Muennig, 2008), usage of such media strategies that increase the stigma associated with "fat body imagery" should be used with caution. Nonetheless, research is critically needed to develop cultural sensitive strategies to assist the community overcome their weight misperception that hinder the effects of any obesity preventive measures in Hispanics.

Although media-related intervention is important, it is only one type of obesity prevention strategy for Hispanics. Without prompt, participants in the current study were able to identify multiple risk factors at the micro and macro-levels that were perceived as contributors to the obesity problem in the Hispanic community. It is encouraging that participants understood that obesity was a multifaceted health problem caused by a variety of factors. In addition to cultural foods and unhealthy eating habits, busy life and lack of exercise, participants perceived the food industry as a major contributor to obesity, and regulation through policy would help the community to engage in healthier eating habits. They also perceived that poverty and food insecurity hindered people's ability to make healthy food choices. Participants articulated a wide-array of solutions to address the obesity epidemic in their community, which were in line with CDC's comprehensive obesity strategies (Keener et al., 2009). Participants appreciated the on-going government and school-based obesity prevention efforts underway in the San Antonio community. However, they also believed that more preventive actions are needed. Government, schools and the media were identified as key entities who could 
offer health education and programming to increase the community's knowledge of practicing healthier habits. Moreover, healthfriendly environments such as communities with parks, sidewalks and affordable gym classes would facilitate active living. At an individual and interpersonal level, participants pointed out that personal responsibility, parental role modeling and peer support play significant roles in the battle against obesity.

While the current study provided great insight about the perception of obesity among Hispanics, there were several limitations associated with this qualitative study. First, although a purposeful sampling strategy was used, like other qualitative studies of this nature, participants may have self-selected to participate in a study because they have a keen interest and substantial knowledge about health issues; their opinion may not reflect the general publics' opinion. Secondly, although this study made every effort to minimize bias by avoiding leading questions, social desirability may have still influenced participant responses. In addition, there was a more significant amount of females than males participating in this study. The length of living in the United States could also have influenced participants' responses during the interviews. Lastly, we did not include information about the language of preference when using media in the demographic questionnaire. Nonetheless, these findings generated rich data to inform readers on methods for developing obesity prevention strategies and may be relevant and applicable to communities with similar settings and characteristics.

\section{Conclusions and Implications}

Hispanic residents are concerned with obesity and were able to suggest potential solutions to address the escalating obesity problem. Spanish media represent a promising venue to inform, educate and motivate the Hispanic community to live a healthier lifestyle and thus reduce the risk of obesity and diabetes. Future media-related obesity prevention strategies should consider using TV and Internet as the main channels of health communication, utilizing celebrities as message sources in educating the community about living a healthy lifestyle, and focusing on frequent public health announcements of local government initiatives, programs and events; as well as advocating regulation on junk food commercials. Future research is needed to analyze the current health communication content regarding obesity in major Spanishlanguage media sources. Also, future research using a quantitative approach is needed to confirm the finding from the current qualitative study. Content analysis of the current obesity-related health information in major Spanish-language media sources will help better develop effective health communication through the media. In addition, research is also needed to explore the potential effect of "fat body imagery" on changing the Hispanic community's weight perception. Such studies should be conducted with caution to avoid psychological issues in the community.

\section{Acknowledgment}

Authors would like to acknowledge the insightful contributions from Dr. Fernando Guerra, Timothy Jones, David Bustos, Arely Perez, Daisy Escamilla, Rosalie Aguilar, David Castillo, Christian Umana, \& the Department of Health and Kinesiology at UTSA.

\section{References}

1. Azevedo, G. D., Duarte, J. M., Souza, M. O., Costa-E-Silva, T. D., Soares, E. M., and Maranhao, T. M. (2006) "Menstrual cycle irregularity as a marker of cardiovascular risk factors at postmenopausal years," Arquivos Brasileros de Endocrinologia $y$ Metabologia, 50 876-883.

2. Brodie, M., Kjellson, N., Hoff, T. and Parker, M. (1999) "Perceptions of Latinos, African Americans, and whites on media as a health information source" Howard Journal of Communications," 10 (3) 147-167. 
3. Brown, K., Johnson, B. and Morrison, M. (2008) "Hispanic fact pack 2008 edition: Annual guide to Hispanic marketing and media," Advertising Age. [Online]. [Retrieved August 28, 2011], http://adage.com/images/random/datacent er/2008/hispfactpack08.pdf

4. Center for Disease Control and Prevention (CDC). (2009) "Morbidity and mortality weekly report: Differences in prevalence of obesity among black, white, and Hispanic adults in the US, 2006-2008," [Online]. [Retrieved May 28, 2011], http://www.cdc.gov/mmwr/preview/mmwr $\mathrm{html} / \mathrm{mm} 5827 \mathrm{a} 2 . \mathrm{htm}$

5. Center for Spanish Language Media. (2010) "The state of Spanish language media: 2010 annual report," [Online]. [Retrieved May 28, 2011], http://www.spanishmedia.unt.edu/spanish/ downloads/annualreport/Sofslm2010.pdf

6. Chatterjee, N., Blakely, D. E. and Barton, C. (2005) "Perspectives on obesity and barriers to control from workers at a community center serving low-income Hispanic children and families," Journal of Community Health Nursing, 22 (1) 23-36

7. Clayman, M. L., Manganello, J. A., Viswanath, K., Hesse, B. W. and Arora, N. K. (2010) "Providing health messages to Hispanics/Latinos: understanding the importance of language, trust in health information sources, and media use," Journal of Health Communication, 15 (3) 252-263

8. Contento, I. R., Basch, C. and Zybert, P. (2003) "Body image, weight, and food choices of Latina women and their young children," Journal of Nutrition Education and Behavior, 35 236-248

9. Crespo, C. J., Smit, E., Carter-Pokras, O. and Andersen, R. (2001) "Acculturation and leisure-time physical inactivity in Mexican American adults: results from NHANES III, 1988-1994. American Journal of Public Health, 91, 1254-1257
10. Duncan, D. T., Wolin, K. Y., Scharoun-Lee, M., Ding, E. L., Warner, E. T., Bennett, G. G. (2011). Does perception equal reality? Weight misperception in relation to weightrelated attitudes and behaviors among overweight and obese US adults. International Journal of Behavioral Nutrition and Physical Activity, 8(20), 1-9

11. McGuire W. (1989), Theoretical foundations of campaigns, InPublic Communication Campaigns, Sage Publications, Rice, R. and Atkin, C. (ed) pp. 43-65. Newbury Park, California

12. Hayes, M. G., Pluzhnikov, A., Miyake, K., Sun, Y., Ng, M. C., and Roe, C. A. (2007) "Identification of type 2 diabetes genes in Mexican Americans through genome-wide association studies," Journal of Diabetes, 56 3033-3044

13. Keener, D., Goodman, K., Lowry, A., Zaro, S. and Kettel Khan, L. (2009) "Recommended community strategies and measurements to prevent obesity in the United States: Implementation and measurement guide," [Online]. [Retrieved June 21, 2011], http://www.cdc.gov/obesity/downloads/co mmunity_strategies_guide.pdf

14. Muennig, P. (2008) "The body politic: The relationship between stigma and obesity-associated disease," BMC Public Health, 8128

15. National Hispanic Caucus of State Legislators. (2011) "Hispanic obesity: an American crisis," [Online]. [Retrieved October 13, 2011], http://nhcsl.org/Hispanic-Obesity-AnAmerican-Crisis.pdf

16. Patton M. Q. (1987). How to use qualitative methods in evaluation, Sage Publications, London

17. Patton, M. Q. (1990). Qualitative evaluation and research methods (2 ${ }^{\text {nd }}$ ed.), Sage Publications, Newbury Park, CA

18. Ramirez, A. G., Chalela, P., Gallion, K. and Velez, L. F. (2007) “Energy balance feasibility 
study for Latinas in Texas: a qualitative assessment," Journal of Preventive Chronic Diseases, 4 (4) 1-12

19. Reininger, B. M., Barroso, C. S., MitchellBennett, L., Cantu, E., Fernandez, M. E. and Gonzalez, D. A. (2010) "Process evaluation and participatory methods in an obesityprevention media campaign for Mexican Americans," Journal of Health Promotion Practice, 11 347-357

20. U. S. Census Bureau. (2009) "Percentage of Hispanics by state, city, county or zone," [Online]. [Retrieved May 23, 2011], http://factfinder.census.gov/servlet/TMSele ctedDatasetPageServlet?_lang=en

21. U. S. Census Bureau. (2009) "Language Spoken at Home," [Online]. [Retrieved May 23 , 2011], http://factfinder.census.gov/servlet/STTable ?_bm=y\&-geo_id=01000US\&qr_name=ACS_2009_1YR_G00_S1601\&ds_name=ACS_2009_1YR_G00_\&-_lang=en\&redoLog=false

22. U. S. Census Bureau. (2011) "The Hispanic Population 2010," [Online].
[Retrieved May 23, 2011], http://www.census.gov/prod/cen2010/brie fs/c2010br-04.pdf

23. Vargas, L.C. and De Pyssler, B.J. (1999) "U.S. Latino newspapers as health communication resources: A content analysis," Howard Journal of Communications, 10 (3) 189-205

24. Ver Ploeg, M. L., Chang, H. and Lin, B. (2008) "Over, under, or about right: Misperceptions of body weight among food stamp participants," Journal of Obesity, 16 2120-2125

25. Wammes, B., Oenema, A. and Brug, J. (2007) "The evaluation of a mass media campaign aimed at weight gain prevention among young Dutch adults," Journal of Obesity, 15 2780-2789

26. Windschitl, P. D., Martin, R. and Flugstad, A. R. (2003) "Context and the interpretation of likelihood information: The role of intergroup comparisons on perceived vulnerability," Journal of Personality and Social Psychology, 82 (5) 742-755

Roger Figueroa, Erica Sosa, Alberto Cordova, Summer Wilmoth, Meizi He and Sa Wu (2014), Journal of Research in Obesity, DOI: 10.5171/2014. 722324 